\title{
USO DE REDES NEURAIS ARTIFICIAIS PARA ANÁLISE DA RESISTÊNCIA À COMPRESSÃO DE PELOTAS QUEIMADAS DE MINÉRIO DE FERRO*
}

\author{
Camila Cristina Nascimento Rodrigues ${ }^{1}$ \\ Renan Carreiro Rochar ${ }^{2}$ \\ Lumena Glória de Souza Nunes ${ }^{3}$ \\ Sayd Farage David ${ }^{4}$ \\ Felipe Farage David ${ }^{5}$ \\ Marcelo Lucas Pereira Machado ${ }^{6}$
}

\begin{abstract}
Resumo
No tocante a qualidade da pelota de minério de ferro, a resistência à compressão é uma das propriedades mais importantes. Utilizando redes neurais artificiais este trabalho teve como principal objetivo a análise da influência de variáveis de processo na resistência à compressão da pelota queimada de minério de ferro. Para isso, foi analisado um banco de dados de 90 dias de produção de pelotas para alto forno de uma usina de pelotização do estado do Espírito Santo. Então desenvolveu-se um modelo matemático por rede neural artificial para predizer a resistência à compressão das pelotas de minério, que avaliou a influência de variáveis metalúrgicas, de ajustes de processo e operacionais. A rede neural mostrou-se capaz de prever a resistência a compressão de maneira satisfatória com um $R^{2}$ de 0,91 . Por fim, constatou-se que o percentual de carbono fixo é a variável que possuí maior influência sobre a resistência à compressão, seguida pela velocidade de grelha e a basicidade binária.
\end{abstract}

Palavras-chave: Redes neurais artificiais; Resistência à compressão; Pelotas de minério de ferro.

\section{USE OF ARTIFICIAL NEURAL NETWORKS TO ANALYSE COMPRESSIVE STRENGTH OF FIRED IRON ORE PELLETS}

\section{Abstract}

As regards the quality of the iron ore pellet, the compressive strength is one of the most important properties. Using artificial neural networks this work aimed to analyze the influence of process variables on the compressive strength of the fired iron ore pellet. For this, a 90 days database of pellets production for blast furnace of a pelletizing plant in Espírito Santo state was analyzed. Then a mathematical model was developed using artificial neural network to predict the compressive strength of the iron ore pellets. The model evaluated the influence of metallurgical, operational and process adjustments variables. The neural network showed to be able to predict the pellets compressive strength satisfactorily with an $\mathrm{R}^{2}$ of 0.91 . Finally, when analyzing the influence of process variables, it was found that the fixed carbon percentage is the variable that possess greater influence on the compressive strength, followed by the grate speed and the binary basicity.

Keywords: Artificial neural networks; Compressive strength; Iron ore pellets.

1 Engenheira de Produção, Instituto Federal de Educação, Ciência e Tecnologia do Espírito Santo, Cariacica, ES, Brasil.

2 Engenheiro Metalurgista, Mestre, Professor da coordenadoria de ferrovias do Instituto Federal de Educação, Ciência e Tecnologia do Espírito Santo, Cariacica, ES, Brasil. 
3 Aluno de mestrado, Programa de pós-graduação em metalurgia e materiais, Instituto Federal do Espírito Santo, Vitória-ES, Brasil.

4 Engenheiro Metalurgista, Mestre, Professor da coordenadoria de Engenharia Mecânica do Instituto Federal de Educação, Ciência e Tecnologia do Espírito Santo, Cachoeiro de Itapemirim, ES, Brasil.

5 Engenheiro Metalurgista, Mestre, Professor da coordenadoria de Engenharia Mecânica do Instituto Federal de Educação, Ciência e Tecnologia do Sul de Minas Gerais, Congonhas, MG, Brasil.

6 Engenheiro Metalurgista, Doutor, Professor do Programa de Pós Graduação em Engenharia Metalúrgica e Materiais do Instituto Federal de Educação, Ciência e Tecnologia do Espírito Santo, Vitória, ES, Brasil 


\section{INTRODUÇÃO}

A pelotização do minério de ferro surgiu na Europa no início do século $X X$ com o intuito de aproveitar os finos de minério de ferro gerados durante a lavra e 0 beneficiamento, e que não eram aproveitados devido à dificuldade de manuseio e transporte, além de diminuir a eficiência dos altos-fornos devido a sua baixa granulometria [1]. O processo de pelotização do minério de ferro pode ser dividido em três fases: a preparação das matérias primas, o processo de pelotamento e por fim o processo de queima que confere a resistência mecânica e as propriedades finais das pelotas $[1,2]$.

O Brasil é o maior produtor de pelotas de minério de ferro do mundo. Entretanto no ano de 2016 as exportações de pelotas, tiveram fraco desempenho, declinando em $42,5 \%$ e 53,7\%, em volume e valor, respectivamente. Embora a continua queda do preço do minério se prolonga desde 2011, as especificações de qualidade da pelota continuam rígidas [1,3].

No tocante a qualidade da pelota a resistência à compressão é uma das propriedades mais importantes. Pelotas com boa resistência mecânica resistem mais às solicitações de natureza física relacionadas às etapas de manuseio, transporte até sua finalidade como insumo no alto forno. Entretanto, o processo de produção deste commoditie é de natureza complexa o que leva a grande dispersão nas propriedades finais da pelota.

Os fatores que afetam as características são de origem diversificada e estão associados às propriedades químicas, físicas e metalúrgicas dos minérios, dos insumos, além de características do processo. Todos esses fatores atuam de maneira sinérgica o que torna a previsão das características da pelota queimada algo complexo e tem fomentado o desenvolvimento de diversas pesquisas acerca da temática $[4,5,6,7]$.

A simulação por redes neurais tem se mostrado uma importante ferramenta no auxílio ao desenvolvimento de modelos que fazem previsão e controle de processos industriais. No trabalho foi desenvolvido um modelo por redes neurais com 0 objetivo de predizer a resistência à compressão das pelotas queimadas verificando a influência de variáveis operacionais como velocidade de movimentação da grelha e temperatura do forno, além das influências metalúrgicas, físicas e de ajuste de processo como, basicidade binária, quantidade de carbono fixo, granulometria e superfície específica da polpa prensada.

\subsection{Processo de pelotização}

A pelotização é a tecnologia para transformar finos e superfinos em partículas maiores de formato esférico conhecidas como pelotas, este processo (Figura 1) é dividido em três grandes estágios: Preparação de matéria-prima, Pelotamento e Processamento térmico ou queima [8].

O processo inicia-se no preparo da qualidade da pilha de finos de minério, conhecidos como pellet feed. Esse minério recebe adição de insumos para garantir a qualidade das pelotas produzidas, em termos de características físicas, químicas e metalúrgicas, necessárias nos próximos estágios (pelotamento e queima) [1]. Carvão mineral (antracito), calcário, magnesita, bentonita, aglomerantes orgânicos e, em alguns casos, cal hidratada são os principais insumos utilizados na pelotização. Após a adição dos insumos ao pellet feed em proporções adequadas, é feita uma 
mistura dos mesmos para que se obtenha uma perfeita homogeneização do material a ser alimentado nos discos ou tambores de pelotamento.

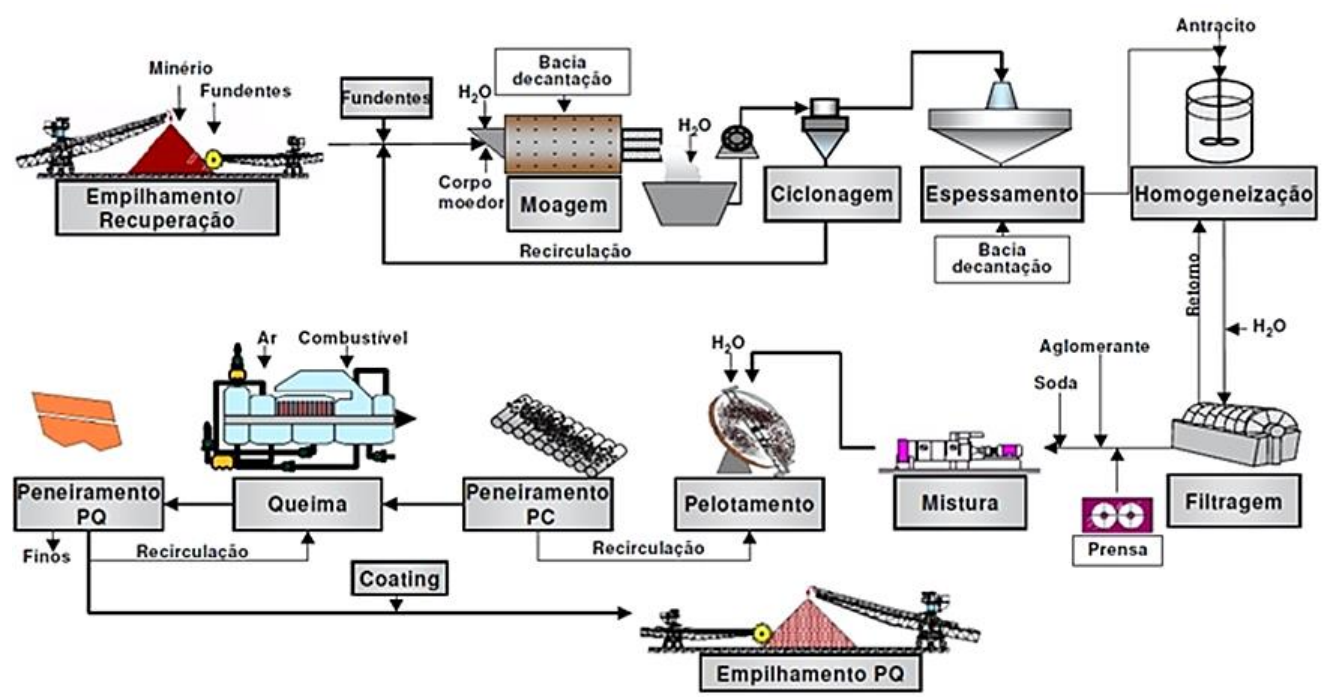

Figura 1. Processo de pelotização [9]

$\mathrm{Na}$ etapa de pelotamento, o pellet feed já na granulometria adequada e com a adição dos insumos necessários, é alimentado nos discos ou tambores de pelotamento, onde acontece a formação das pelotas cruas de minério de ferro. Recebe o nome de pelotas cruas ou verdes, as pelotas que ainda não possuem alta resistência mecânica, sua resistência é somente a necessária para o manuseio local [10].

Para manter uma maior uniformidade das pelotas que alimentaram o forno, as pelotas cruas são classificadas ao saírem do disco de pelotamento e reclassificadas na entrada do forno de endurecimento. Esta etapa de classificação é realizada por uma mesa que rolos, onde as pelotas abaixo e as pelotas acima das especificações são rejeitadas e coletadas por correias transportadoras que retornam ao estágio de pelotamento [1]. As pelotas cruas dentro das especificações $(8-18 \mathrm{~mm})$ seguem para o forno de endurecimento.

A etapa de Queima ou Processamento térmico é a etapa mais onerosa do processo de pelotização, ela é realizada para garantir que as pelotas irão resistir às operações de manuseio e transporte até o cliente e para que as mesmas suportem as pressões dentro dos reatores de redução durante a produção de aço a qual se destinam. As reações químicas que acontecem no processo de queima propiciam 0 endurecimento das pelotas e garantem a resistência física desejada.

\subsection{Redes Neurais Artificiais}

As Redes Neurais Artificiais (RNA) são técnicas computacionais que apresentam um modelo matemático inspirado na estrutura neural de organismos inteligentes e que adquirem conhecimento através da experiência [11]. O princípio de funcionamento da RNA é o mesmo do cérebro de um mamífero, onde as informações são processadas por uma rede de neurônios. Um neurônio artificial (Figura 2) possuí três elementos básicos: as sinapses ou conexões de entrada, a junção de soma (Ativação) e a função de ativação ou transferência.

As RNA passam por um processo de aprendizagem no qual os parâmetros livres de uma rede neural são adaptados através de um processo de estímulo pelo ambiente 
no qual a rede está inserida. O tipo de aprendizagem é determinado pela maneira na qual a modificação dos parâmetros ocorre.

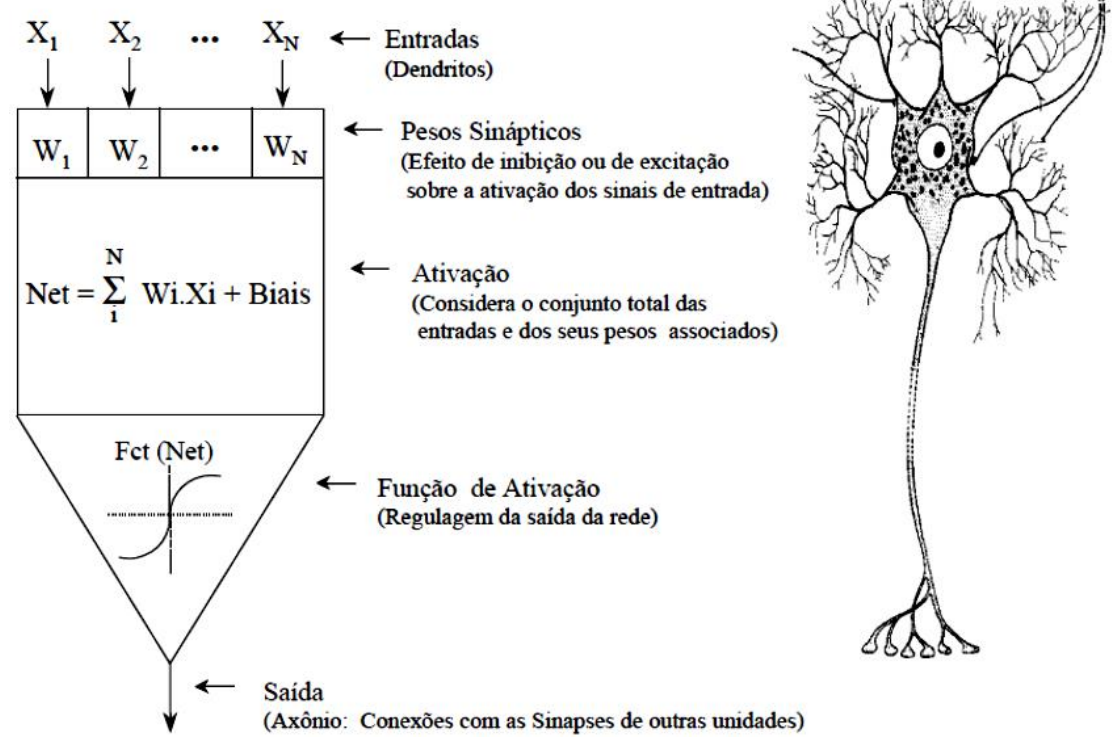

Figura 2. Modelo de neurônio artificial [12]

A aprendizagem supervisionada envolve a modificação dos pesos sinápticos de uma rede neural através da aplicação de um conjunto exemplos de tarefas. Cada exemplo é constituído por um sinal de entrada único e uma resposta correspondente desejada. A rede é apresentada com um exemplo escolhido aleatoriamente a partir do conjunto, e os pesos sinápticos da rede são modificados para minimizar a diferença entre a resposta desejada e a resposta real da rede produzida pelo sinal de entrada de acordo com um critério estatístico apropriado. Este processo é repetido diversas vezes, assim, a rede aprende com os exemplos através da construção de um mapeamento de entrada-saída para o problema [13]. Uma rede neural treinada para operar num ambiente específico pode ser facilmente reciclada para lidar com pequenas alterações nas condições ambientais de operação.

Uma RNA, devidamente treinada, possuí capacidade de generalização, isto é, a capacidade de responder coerentemente a padrões desconhecidos. Ao termo padrões desconhecidos fica subentendido que seja um conjunto de padrões extraído da mesma população dos conjuntos de dados de treinamento, ou seja, dados com mesmas características estatísticas dos padrões de treinamento [14]. Cada problema abordado requer uma quantidade de amostras capaz de representá-lo. A escolha da arquitetura do modelo neural adequada à complexidade do problema é um dos maiores desafios no estudo da capacidade de generalização.

\section{MATERIAIS E MÉTODOS}

\subsection{Seleção das variáveis de entrada}

No trabalho buscou-se um modelo de rede neural artificial que fosse capaz de verificar as influências das matérias-primas e variáveis de processo na resistência a compressão das pelotas queimadas, que segundo Costa [5] é um dos principais índices de medição de resistência física das pelotas.

Os dados utilizados na simulação são de uma grande empresa de mineração localizada no estado do Espírito Santo. O banco de dados apresentava dez variáveis 
de processo em 90 dias de produção de pelotas de minério de ferro do tipo alto forno em uma usina de pelotização.

No quadro 1 são apresentadas as variáveis de entrada (ou independentes) e a variável de saída (ou dependente) usadas nas fases de treinamento e teste das redes neurais artificiais.

Quadro 1. Variáveis de entrada e saída das RNA

\begin{tabular}{|c|c|c|}
\hline & Variável & Unidade \\
\hline 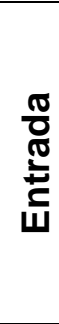 & $\begin{array}{c}\text { Carbono fixo } \\
\text { Basicidade } \\
\text { Granulometria de Polpa Prensada } \\
<0,045 \mathrm{~mm} \\
\text { Superfície Específica de Polpa Prensada } \\
\text { Temperatura de Topo } \\
\text { Velocidade de grelha }\end{array}$ & $\begin{array}{c}\% \\
- \\
\% \\
\mathrm{~cm}^{2} / \mathrm{g} \\
\stackrel{\circ}{\mathrm{C}} \\
\mathrm{m} / \mathrm{min}\end{array}$ \\
\hline 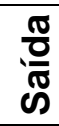 & Compressão & Kgf/pelota \\
\hline
\end{tabular}

\subsection{Tratamento de dados}

Para construir modelos baseados em processos industriais deve-se fazer algumas considerações, já que dados inconsistentes podem ocorrer devido a diversos fatores, tais como [15]:

a) Ruídos nos dados de processo;

b) Erros na medição dos dados do processo;

c) Erros no manuseio dos dados (leitura ou digitação);

d) Erros no tratamento dos dados.

A partir do banco de dados fornecido pela empresa mineradora foi realizado o tratamento dos dados utilizando-se gráficos do tipo box plot para identificar valores outliers, também conhecidos como pontos fora do padrão. Todas as análises relacionadas ao tratamento de dados e desenvolvimento de RNAs foram realizadas utilizando o software STATISTICA 8.

Os dados identificados como outliers representam dias onde a qualidade da pelota não foi normal, devido a fatores diversos, como baixa produção, falta de preenchimento de alguma variável por operadores, utilização de qualidade média do parâmetro em virtude de uma parada de produção, dentre outros. Estes dados fora do padrão foram removidos para que o treinamento da rede não fosse influenciado por valores que não condizem com o processo da usina.

\subsection{Arquitetura da rede neural artificial}

Para determinar as funções de transferência da camada de entrada e da camada de saída foram implementadas 750 RNAs permutando as funções tangente hiperbólica (Tanh), logística (Logis) e exponencial (Expo) e o número de neurônios na camada escondida. $O$ desempenho de cada grupo será medido pelo erro (Esos) durante a fase de treinamento.

O número de neurônios da camada intermediária é em geral definido de maneira experimental e depende de vários fatores [16], tais como:

a) Número de exemplos de treinamento; 
b) Quantidade de ruído nos exemplos;

c) Complexidade da função a ser aprendida;

d) Distribuição estatística dos dados de treinamento.

Para obter a melhor arquitetura para as RNA foram implementados diversos modelos variando o número de neurônios na camada intermediária de $n / 2$ até $2 n+1$, sendo $\mathrm{n}$ o número de entradas da rede [14].

\subsection{Treinamento da rede}

O algoritmo de treinamento foi do tipo backpropagation usando a minimização dos erros através do algoritmo BFGS.

O Erro foi avaliado pela soma das diferenças entre o alvo e as saídas de predição definidas sobre o conjunto inteiro de treinamento, conhecido como soma dos quadrados (sum-of-squares), Equação 1.

$$
E_{S O S}=\sum_{i=1}^{n}\left(y_{i}-t_{i}\right)^{2}
$$

No qual n é o número de casos de treinamento e $y_{i}$ é o valor das saídas da rede do valor-alvo $t_{i}$. Quanto maior for a diferença entre a predição da rede e os alvos maior será o valor do erro, portanto o algoritmo de treinamento deve continuar a ajustar os pesos até encontrar a melhor rede $[13,14]$.

\subsection{Avaliação dos resultados}

Os resultados obtidos pelas redes neurais foram avaliados através de gráficos de correlação e da comparação com outros cinco trabalhos publicados na área que analisaram a variável resistência à compressão.

A análise de sensibilidade faz o relacionamento entre as variáveis de entrada e saída das RNAs para determinar a influência de cada variável nos resultados [17].

A sensibilidade global analisa e dá informações sobre a importância relativa das variáveis usadas em uma rede neural. $\mathrm{Na}$ análise de sensibilidade global, o conjunto de dados é enviado para a rede várias vezes, com cada variável sendo substituída por seu valor médio calculado a partir da amostra de treinamento, e o erro de rede resultante é gravado. Se uma variável importante sofre alteração, o erro vai aumentar muito, já se uma variável sem importância é removida, o erro não sofrerá grandes alterações [18].

\section{RESULTADOS E DISCUSSÃO}

$\mathrm{Na}$ figura 3 são representados os resultados dos treinamentos, cada ponto do gráfico representa uma rede neural com um determinado número de neurônios na camada escondida representado no eixo das abscissas e com o seu valor do erro durante a fase de treinamento indicado no eixo das ordenadas. Os grupos são diferenciados pelas cores e formatos dos pontos como mostra a legenda. São apresentadas somente as 100 melhores redes neurais das 750 RNAS treinadas, foram escolhidas as RNAS com o menor erro obtido durante o treinamento. 


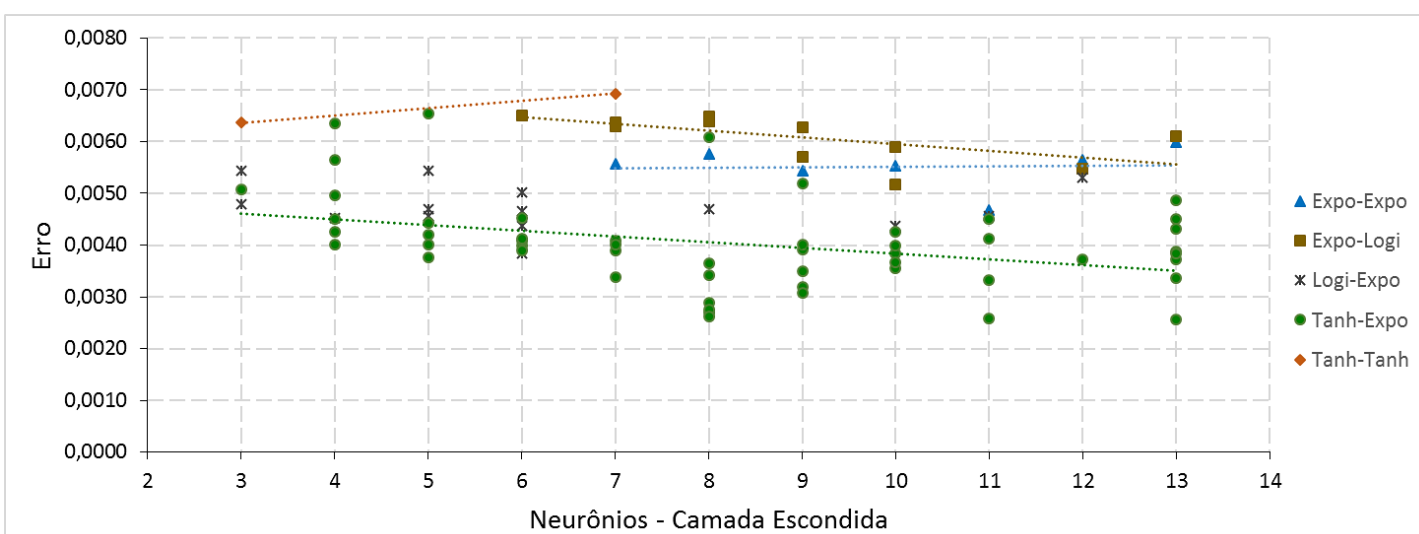

Figura 3. Comportamento do erro (Esos) durante a fase de treinamento variando o número de neurônios da camada escondida e função de transferência.

De acordo com a figura 3 percebe-se que o grupo RNA "Tanh-Expo" possuí os menores valores de erro, portanto a partir deste resultado foram implementadas 100 redes neurais com configuração das funções de transferência de Tangente hiperbólica na camada escondida e Exponencial na de saída, variando o número de neurônios na camada escondida, de 3 a 13 neurônios, determinando, através do menor erro, a melhor rede neural. Cada ponto do gráfico da figura 4 representa uma rede neural com um determinado número de neurônios na camada escondida, eixo das abscissas, e com o seu valor do erro durante a fase de treinamento, eixo das ordenadas.

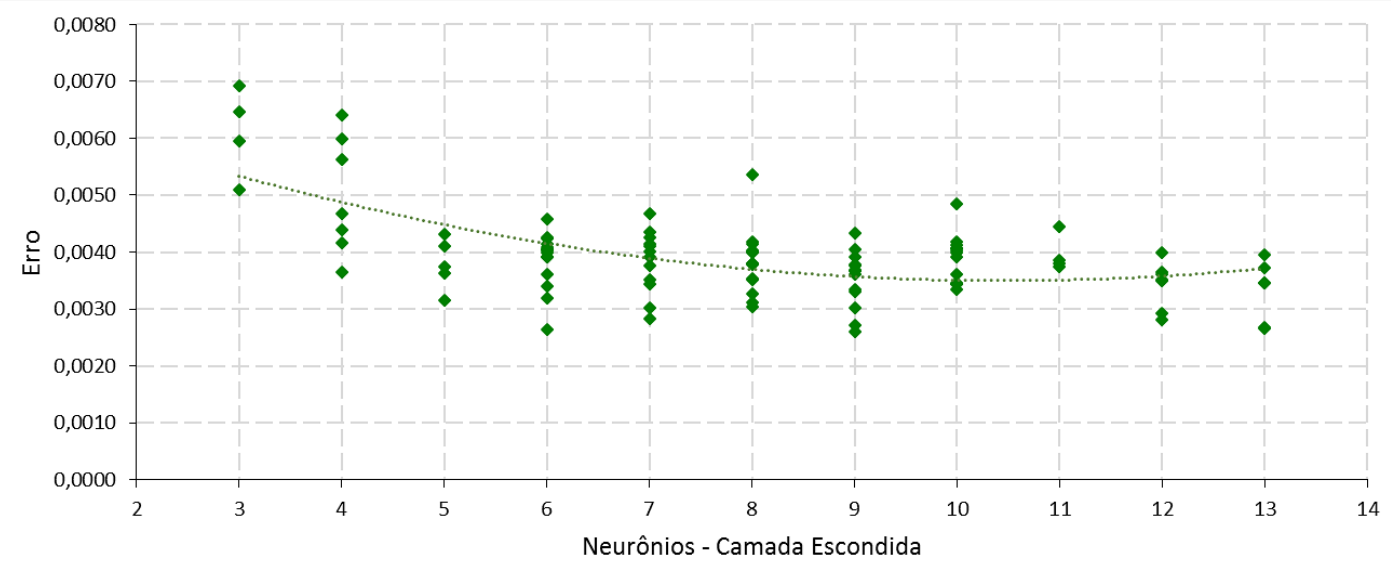

Figura 4. Comportamento do erro (Esos) durante a fase de treinamento com a variação do número de neurônios da camada escondida para as redes neurais do grupo Tanh-Expo.

Observa-se que o fenômeno é melhor modelado com redes neurais com um maior número de neurônio na camada escondida. A rede que apresentou o melhor desempenho possui 9 neurônios na camada escondida, e o quadro 2 apresenta a sua configuração:

Quadro 2. Configuração da rede neural

\begin{tabular}{|l|cc|}
\hline Função/ variável de Saída & Camada Escondida & Camada de Saída \\
\hline Função de Transferência & Tangente hiperbólica & Exponencial \\
№ Neurônios & \multicolumn{2}{|c|}{ Multicamadas } \\
Tipo de RNA & \multicolumn{2}{|c|}{ BFGS } \\
Algoritmo de treinamento & \multicolumn{2}{|c|}{ BFG }
\end{tabular}


$\mathrm{E}_{\mathrm{SOS}}$

A rede neural artificial durante as fases de treinamento e teste apresentou correlação, $R^{2}$, de 0,943 e 0,911 , respectivamente. O erro, Esos, encontrado na fase de treinamento foi de 0,00260 e 0,01168 para a fase de teste. Através desses índices pode-se verificar a assertividade desse modelo em predizer a compressão da pelota queimada de minério de ferro. A figura 5 mostra a representação gráfica da correlação entre os valores real e estimado para a variável compressão.

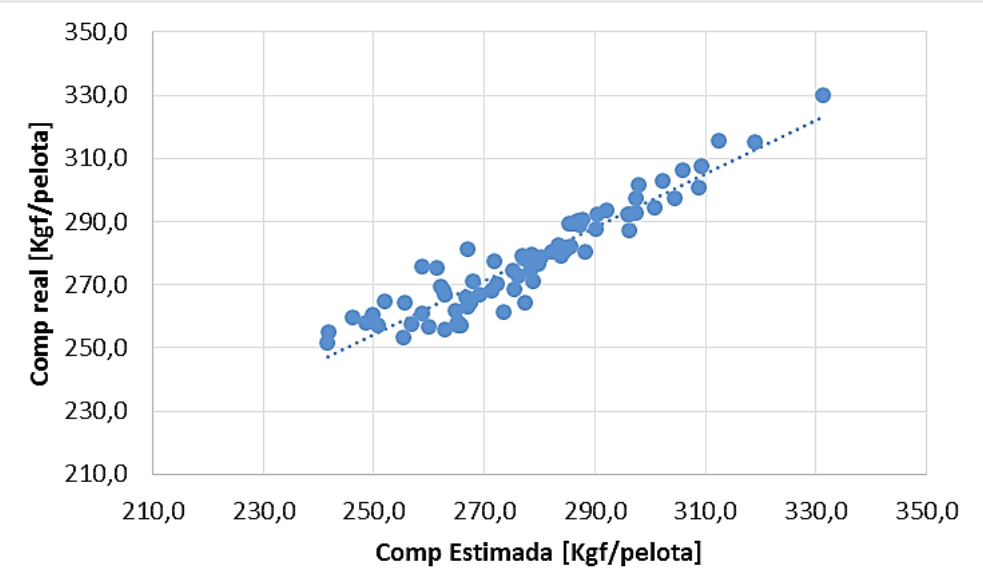

Figura 5. Correlação do valor de compressão real com o valor estimado

A figura 6 mostra que o modelo possui uma boa concordância entre os valores reais e os calculados no período analisado.

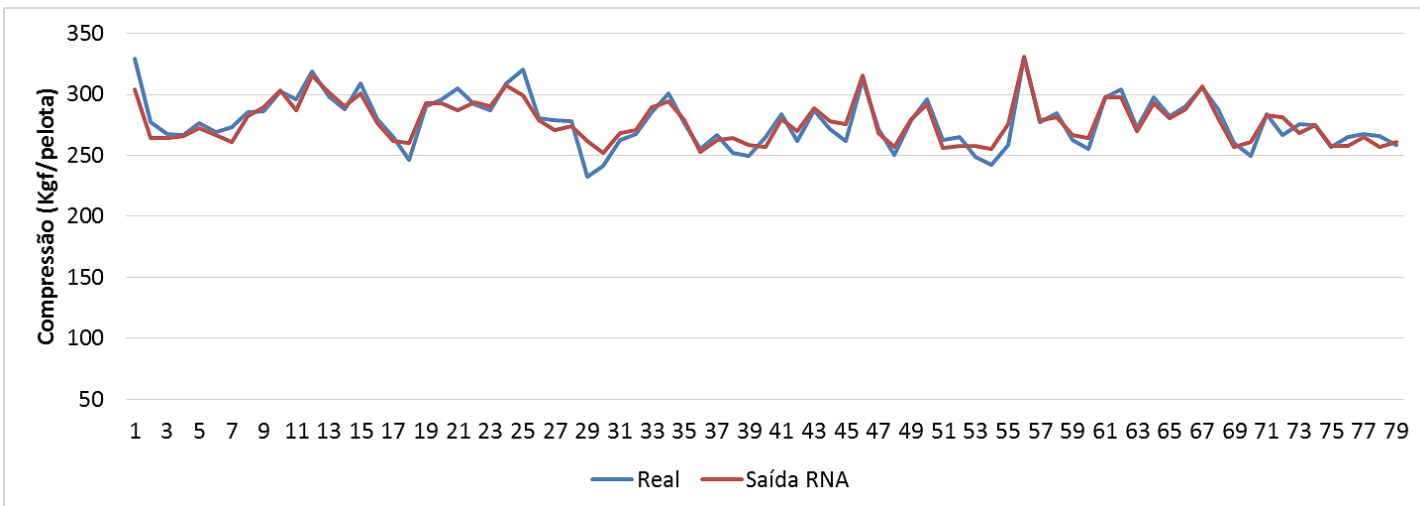

Figura 6. Comparação entre o valor de compressão real e o estimado pela RNA

A capacidade de predição da RNA proposta foi comparada com outros cinco modelos publicados que utilizaram três metodologias: Redes Neurais Artificiais, Regressão Linear múltipla e Engenharia Robusta. Os trabalhos de Srinivas [4] e Gerhard [19] que empregaram redes neurais artificiais encontraram $\mathrm{R}^{2}$ de $0,75 \mathrm{e}$ 0,52, respectivamente. Ao utilizar Regressão linear múltipla, Neto [6] e Sá [7] obtiveram índices de correlação de 0,67 e 0,85. Já Costa [5] ao aplicar a metodologia de Engenharia robusta encontrou um $\mathrm{R}^{2}$ de 0,94 .

Percebe-se que o modelo proposto por este trabalho possuí o melhor resultado utilizando a metodologia de redes neurais, ficando com o mesmo $\mathrm{R}^{2}$ que o modelo proposto por Costa [5] que utilizou Engenharia robusta. O que indica que as escolhas das variáveis de entrada foram assertivas, permitindo a construção de uma rede neural que permite modelar de maneira satisfatória o fenômeno estudado. 
O quadro 3 mostra os resultados da análise de sensibilidade global obtidos com o uso do software STATISTICA. Verifica-se que as variáveis de maior influência na análise de sensibilidade global são o carbono fixo e a velocidade de grelha, seguidos pela basicidade, enquanto as outras variáveis de entrada apresentam pouca influência na variável de saída, resistência à compressão.

Quadro 3. Análise de sensibilidade global

\begin{tabular}{|l|c|c|}
\hline \multicolumn{1}{|c|}{ Variável } & $\begin{array}{c}\text { Análise de } \\
\text { sensibilidade }\end{array}$ & $\begin{array}{c}\text { Impacto na } \\
\text { resistência à } \\
\text { compressão }\end{array}$ \\
\hline Carbono fixo & 4,04 & - \\
Basicidade & 2,44 & - \\
Granulometria de polpa prensada & 2,24 & + \\
Superfície específica de polpa prensada & 1,98 & + \\
Temperatura de topo & 1,91 & + \\
Velocidade de grelha & 3,58 & - \\
\hline
\end{tabular}

Ao relacionar o percentual de carbono fixo, a velocidade de grelha e a resistência à compressão (Figura 7) verifica-se que com baixo teor de carbono existe uma grande influência da velocidade, entretanto com aumento do carbono fixo esta influência da velocidade é menor, o que permitir produzir em maior velocidade sem grandes prejuízos na qualidade da pelota.

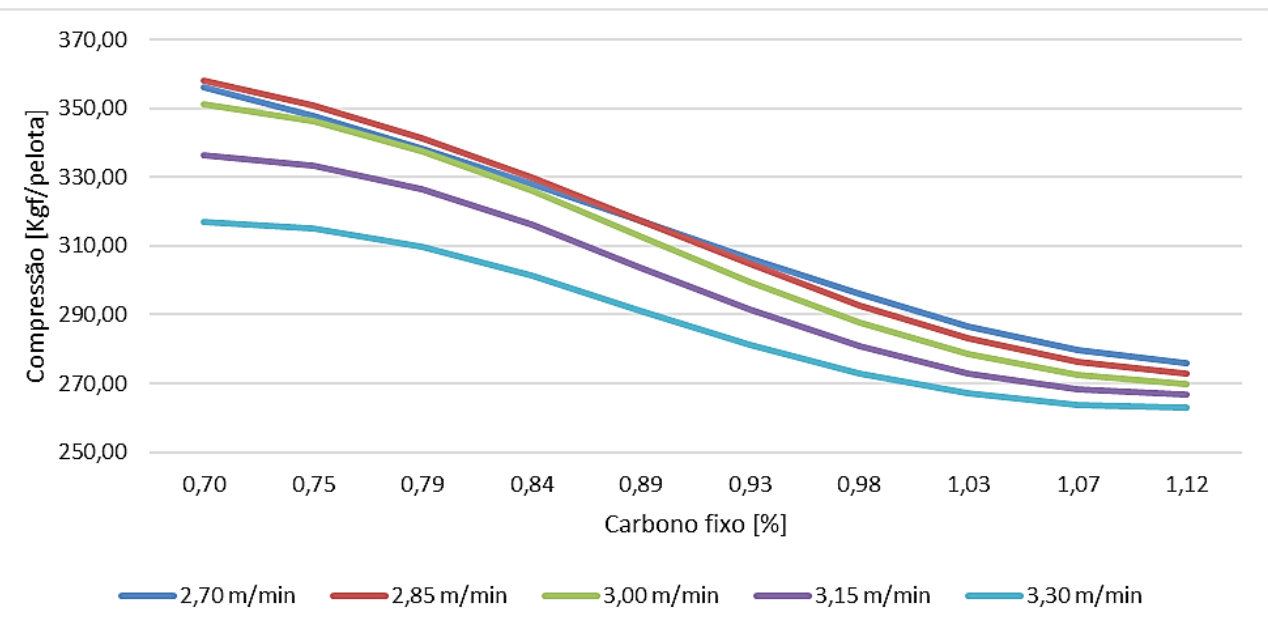

Figura 7. Relação entre carbono fixo, velocidade de grelha e resistência à compressão

Ao analisar o gráfico percebe-se que a resistência à compressão diminui com o aumento do percentual de carbono fixo, isso se deve ao fato de que ao adicionar maior quantidade de antracito, que possui $12,34 \%$ de matéria volátil, visando aumentar 0 teor de carbono na pelota, aumenta-se também o percentual de materiais voláteis que durante o processo de queima no forno são liberados, provocando o aumento da porosidade na pelota e redução de sua resistência física [20]. Entretanto, o carbono fixo na pelota é usado como um segundo combustível no processo de pelotização e devido ao menor custo do antracito, quando comparado ao gás natural, eleva-se a dosagem do mesmo visando redução de custo de produção. Este fato é evidenciado pela figura 8 , ao se adicionar um maior percentual de carbono fixo na pelota há uma redução no custo, por tonelada de pelota, com gás natural. 


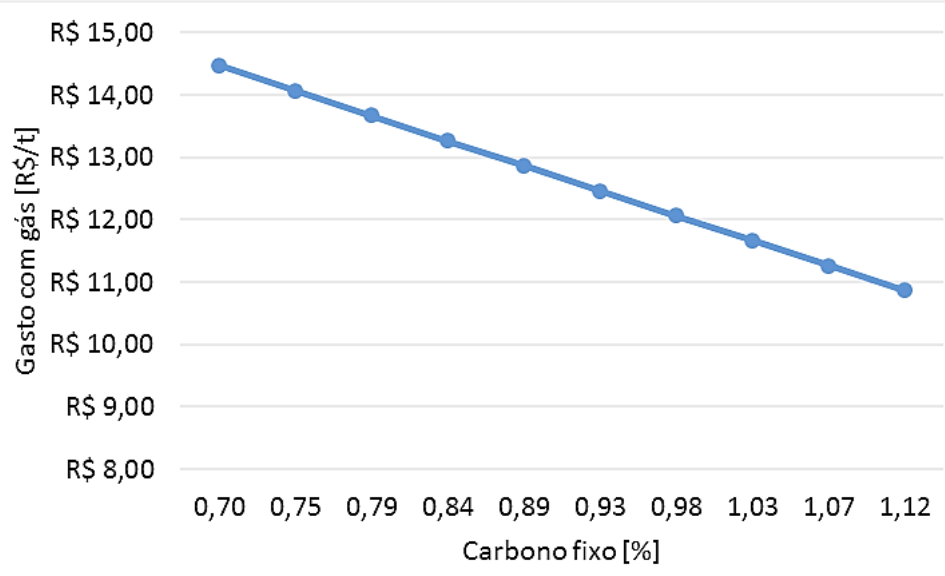

Figura 8. Relação entre consumo de gás e quantidade de carbono fixo

\section{CONCLUSÃO}

A partir dos resultados do presente trabalho, foi possível concluir que:

1. As respostas obtidas com o modelo e o baixo erro mostram a eficiência das redes neurais na modelagem de processos industriais complexos e também a capacidade do modelo de avaliar com precisão o comportamento da qualidade física da pelota de minério de ferro.

2. A resistência à compressão é definida principalmente pelo percentual de carbono fixo presente na pelota, pela basicidade binária e pela velocidade de transporte das pelotas pela grelha, sendo que o aumento das três variáveis implica em impacto negativo na resistência à compressão.

\section{REFERÊNCIAS}

1 Centro de Tecnologia Mineral. Tratamento de minérios. 5 ed. Rio de Janeiro: CETEM, 2010.

2 Meyer K. Pelletizing of Iron Ores. Düsseldorf: Springer-Verlag, 1980.

3 Ministério de Minas e Energia. Brasil exportou US\$ 36,6 bilhões em bens minerais em 2016. [publicação online]. Brasília; 2017 [acesso em 04 abr. 2017]. Disponível em: http://www.brasil.gov.br/infraestrutura/2017/01/brasil-exportou-US-36-bilhoes-em-bensminerais-em-2016

4 Srinivas D, Gupta PK, Rao SM. Prediction of Iron Ore Pellet Strength Using Artificial Neural Network Model. ISIJ International. 2007; Vol. 47 (1): 67-72.

5 Costa, RVP. Otimização da Resistência à Compressão de Pelotas de Minério de Ferro para Redução Direta pela Aplicação de Projeto Robusto. (Dissertação de Mestrado). Ouro Preto: Universidade Federal de Ouro Preto; 2008.

6 Neto NS, Stemiller L, Jesus RW, Tomaz RE. Utilização do método de regressão linear múltipla para análise da resistência à compreensão das pelotas de alto forno. In: $41^{\circ}$ Seminário de Redução de Minério de Ferro e Matérias-Primas, 2011, Vitória. p. 1-10

7 Sá KG, Costa GM, Vieira CB. Efeito da composição mineralógica na resistência a compressão de pelotas de minério de ferro. Tecnologia metalurgia, materiais e mineração. 2004; Vol. 1 (2).

8 Augusto KS. Identificação Automática do Grau de Maturação de Pelotas de Minério de Ferro. (Dissertação de Mestrado). Rio de Janeiro: Pontifícia Universidade Católica do rio de Janeiro; 2012. 
9 Vale. Entenda como funciona o processo de pelotização em nossas usinas. [publicação online]. Vitória; 2014 [acesso em 02 mai. 2017]. Disponível em:

http://www.vale.com/brasil/PT/aboutvale/news/Paginas/entenda-funciona-processopelotizacao-usinas.aspx.

10 Mourão MB, Yokoji A, Malynowskyj A, Leandro CAS, Quites EEC, Gentile EF, Silva GFBL, Bolota JR, Gonçalves M, Faco RJ. Introdução à Siderurgia. São Paulo: ABM, 2007.

11 Cardon A, Müller D. Introdução às Redes Neurais Artificiais. (Dissertação de Mestrado). Porto Alegre: Universidade Federal do Rio Grande do Sul; 1994.

12 Machado M. Controle e simulação de processos. [publicação online]. Vitória; 2012. [acesso em 02 mai. 2017]. Disponível em:

https://sites.google.com/site/marcelolucaspm/disciplinacontrole-e-simulao-de-processos

13 Haykin S. Neural networks and learning machines. 3 ed. Ontario: Pearson, 2009.

14 Takahashi, HJ. Predição de Propriedades Mecânicas de Aços de Alta Resistência Microligados Utilizando Técnicas de Inteligência Computacional. (Dissertação de Mestrado). Coronel Fabriciano: Centro Universitário do Leste de Minas Gerais; 2006.

15 Linkens DA, Nyongesa HO. Real-time acquisition of fuzzy rules using genetic algorithms. Annual Review in Automatic Programming. 1992; Vol. 17: 335-339.

16 Braga ADP, Carvalho APLF, Ludermir TB. Redes neurais artificiais: Teoria e aplicações. 2. ed. Rio de Janeiro: LTC, 2007

17 Oliveira, GO, Pedrollo OC, Castro NMR. Metodologia de análise de sensibilidade e exclusão de variáveis de entrada em simulação hidrológica por redes neurais artificiais (RNAs): resultados preliminares. In: XIX Simpósio Brasileiro de Recursos Hídricos, 2011, Maceió.

18 StatSoft. Performing Regression with 4-Bar Linkage Data. [publicação online]. Palo Alto; 2015. [acesso em 11 abr. 2017]. Disponível em:

http://documentation.statsoft.com/STATISTICAHelp.aspx?path=SANN/Examples/SANN Example1PerformingRegressionwith4BarLinkageData

19 Gerhard M. Estudo da linha 2 de produção de pelotas em Ubu. Relatório de consultoria, 2004,

20 Casagrande C, Macedo F, Guachalla S, Hahn G. Avaliação prensagem de mistura de minério de ferro e carvão em escala piloto. In: 45 Seminário de Redução de Minério de Ferro e Matérias-primas, 16 Simpósio Brasileiro de Minério de Ferro e 3ํ Simpósio Brasileiro de Aglomeração de Minério de Ferro, 2015, Rio de Janeiro. 